http://dx.doi.org/10.18542/rmi.v15i24.10051

Margens: Revista Interdisciplinar | e-ISSN:1982-5374 | V. 15 | N. 24 | Jun, 2021, pp. 103-122

\title{
NECROTERRITÓRIOS: TERRITORIALIZAÇÃO E DESTERRITORIALIZAÇÃO DOS POVOS INDÍGENAS COMO ESTRATÉGIAS NECROPOLÍTICAS
}

\section{NECROTERRITORIES: TERRITORIALIZATION AND DETERRITORIALIZATION OF INDIGENOUS PEOPLES AS NECROPOLITICAL STRATEGIES}

\section{Manoel Rufino David de OLIVEIRA (UFPA/FACI/ESMAC)}

\begin{abstract}
Resumo: $O$ presente estudo busca analisar o território como tecnologia necropolítica de produção de morte dos povos indígenas, a partir da teoria de Achille Mbembe e de Rogério Haesbaert. Em primeiro lugar, será discutido o conceito de necropolítica para, em seguida, ser explicado o processo histórico de genocídio dos povos indígenas. Em terceiro, será analisado o território enquanto tecnologia necropolítica de produção de morte desses povos, principalmente a partir de práticas de territorialização e desterritorialização. A pesquisa é do tipo exploratória, adotou-se o método dedutivo, e utilizam-se como ferramentas de pesquisa a revisão bibliográfica e a documental. Ao final, conclui-se que os territórios do Cerrado e da Amazônia são verdadeiros necroterritórios, nos quais, processos de territorialização e desterritorialização capturam as vidas dos povos indígenas e produzem seu extermínio em massa em resposta às necessidades do capital do agronegócio.
\end{abstract}

Palavras-chave: Necropolítica. Genocídio. Território. Povos indígenas.

\begin{abstract}
: this study aims to analyze the territory as a necropolitical technology to produce death of indigenous peoples, based on the theory of Achille Mbembe and Rogério Haesbaert. Firstly, we discussed the concept of necropolitics, and then we explained the historic process of genocide of indigenous peoples. Third, we analyzed the territory as a necropolitical technology to produce death of these peoples, mainly based on practices of territorialization and deterritorialization. The research is exploratory and adopts the deductive method, using bibliographic and documentary review as research tools. In the end, we concluded that the territories in the Cerrado and in the Amazon are truly necroterritories, in which processes of territorialization and deterritorialization capture the lives of indigenous peoples and produce their mass extermination in response to the needs of agribusiness capital.
\end{abstract}

Keywords: Necropolitics. Genocide. Territory. Indigenous peoples.

\footnotetext{
${ }^{1}$ Doutorando em Direitos Humanos pelo Programa de Pós-Graduação em Direito (PPGD) da Universidade Federal do Pará (UFPA), na linha de pesquisa "Estudos Críticos do Direito". Docente na Universidade Federal do Pará (UFPA), na Faculdade Faci Devry Belém e na Escola Superior Madre Celeste (ESMAC). E-mail: manoelrufinoadv@gmail.com
} 


\section{INTRODUÇÃO}

No dia 12 de junho de 2020, dois jovens indígenas foram executados por garimpeiros invasores da comunidade Xaruna, localizada em Alto Alegre. Essa tensão entre indígenas e garimpeiros pode chegar a um conflito similar ao Massacre de Haximu, ocorrido em 1993, quando garimpeiros promoveram uma chacina contra indígenas Yanomami. Este foi o primeiro caso de genocídio reconhecido pela Justiça do Brasil. Segundo a carta divulgada pela Associação Hutukara Yanomami, estima-se que 20 mil garimpeiros estejam infiltrados na Terra Yanomami, maior território indígena do país, dividido entre Roraima e o Amazonas, com cerca de 26.780 indígenas vivendo na região.

O recente caso é apenas um exemplo de diversos conflitos envolvendo terras indígenas no Brasil. Nos últimos anos, houve um aumento significativo de invasões em terras indígenas e de violência contra povos indígenas, como comprova o "Relatório de violências contra os povos indígenas no Brasil”" (2019), publicado pelo Conselho Indigenista Missionário (CIMI). A usurpação de terras tradicionais, as chacinas, os assassinatos e a proliferação de doenças contagiosas não são fenômenos apartados e sem correlação, pois fazem parte de um projeto de genocídio de povos originários que vem sendo colocado em prática desde o período colonial brasileiro.

Em estudo acerca da produção de mortes massificadas no contexto das ocupações coloniais, Achille Mbembe denominou de "necropolítica" o conjunto de técnicas voltadas para o "fazer viver, fazer morrer". O filósofo camaronês sustenta que o necropoder permanece nas sociedades contemporâneas, principalmente nos países que tiveram experiência colonial, e onde a raça foi utilizada para criar um estado de exceção permanente, cujos limites do poder soberano de produzir a morte não mais existem. Nesses locais, o governo necropolítico produz a morte de certas populações para que determinadas populações possam viver.

No contexto brasileiro, verifica-se que, desde o período colonial, o genocídio da população não branca é uma estratégia utilizada pelo governo necropolítico para assegurar a sobrevivência da população branca. Atualmente, os espaços naturais do Cerrado e da Amazônia apresentam-se como necroterritórios, nos quais as mortes em massa ocorrem sob estado de exceção permanente. Processos como territorialização e desterritorialização foram desde o período colonial utilizados como tecnologias necropolíticas de produção de morte dos povos indígenas e produção de vida dos povos brancos. 
Com base nas questões arguidas acima, adotou-se a seguinte indagação de pesquisa para este trabalho: em que medida o território pode ser uma tecnologia necropolítica de genocídio dos povos indígenas?

E, para responder a essa questão, foram definidos os seguintes objetivos específicos: explicar o conceito de necropolítica, conforme proposto por Achille Mbembe; compreender o genocídio dos povos indígenas, desde o período colonial brasileiro até o contexto de redemocratização; e analisar o território enquanto tecnologia necropolítica de genocídio dos povos indígenas, a partir das práticas de territorialização e desterritorialização.

Para pensar a respeito dos efeitos da necropolítica no Brasil para os povos indígenas, é incontornável a abordagem interdisciplinar entre Ciências Sociais, Geografia e Antropologia, a partir de uma revisão bibliográfica que permita a contextualização do conceito de necropolítica de Achille Mbembe ao campo dos estudos geográficos acerca de território e dos estudos indigenistas. Por isso, o presente trabalho busca desenvolver uma reflexão considere não apenas a categoria de necropolítica proposta por Achille Mbembe, mas também as reflexões teóricas de Michel Foucault, Giorgio Agamben e Aníbal Quijano e os estudos em território de Rogério Haesbaert.

\section{NECROPOLÍTICA, UMA CHAVE CONCEITUAL PARA COMPREENDER OS GOVERNOS DO SUL GLOBAL}

Achille Mbembe é um dos intelectuais africanos mais prestigiados na atualidade, sendo reconhecido como um pensador fértil, polêmico e incisivo no campo da Ciência Política. A partir das discussões trazidas em seu ensaio Necropolítica, publicado pela primeira vez em 2003 na revista americana Public Culture e, posteriormente traduzido para várias línguas. Como ressalta Fátima Lima (2018, p. 26), ao cunhar o conceito de necropolítica no campo das Ciências Sociais, Mbembe nos permite pensar a forma de constituição de diagramas de poder não apenas nos contextos pós-coloniais das Áfricas, mas também nos processos de colonização, neocolonização e descolonização dos contextos latino-americanos, caribenhos e brasileiros.

Achille Mbembe (2016, p. 128) parte do princípio de que os efeitos da escravidão e do colonialismo ainda imperam com força no contexto do Sul Global, pois o governo dos países da América Latina, da África e da Ásia ainda funcionam a partir do necropoder e da necropolítica. Nesses locais, o biopoder se utilizaria do estado de exceção, do estado de sítio, da emergência e da noção de inimigo como base normativa do direito de matar, razão pela qual o biopoder se torna o necropoder. 
Nesse caso, "a característica mais original dessa formação de terror é a concatenação do biopoder, o estado de exceção e o estado de sítio" e a raça e o racismo seriam cruciais para esse encadeamento, como explica Mbembe (2016, p. 132).

Assim, "necropoder" e "necropolítica" aparecem como conceitos correlacionados, mas não sinônimos. O "necropoder" seria uma articulação concomitante e simultânea do poder disciplinar, da biopolítica e da necropolítica, no governo de países que foram construídos a partir da experiência colonial. O necropoder agrega um conjunto de tecnologias políticas que atuam para estabelecer a gestão e controle das populações e do indivíduo, mecanismos que são diversos, aparentemente até divergentes, mas que convergem e atuam combinadamente. Por sua vez, a necropolítica é entendida como parte do necropoder, isto é, um conjunto de políticas voltadas para a submissão da vida ao poder da morte, ou como o referido autor denomina, "políticas de morte", que se somam ao poder disciplinar e à biopolítica.

Foucault (2005, p. 294) explica que o poder soberano, na Idade Média, era baseado na lógica de "fazer morrer, deixar viver", que, de maneira ativa, selecionava aqueles que deveriam morrer, e, de maneira passiva, deixava o restante viver. No século 18, a biopolítica surge como um novo tipo de poder aplicado à vida dos homens como massa global, baseado agora na lógica de "fazer viver, deixar morrer", pois esta seleciona, de maneira ativa, aqueles que irão viver, garante, de maneira positiva a permanência de suas vidas e, de maneira passiva, deixa que o restante morra. Ao estabelecer esse paralelo, entende-se que, a partir do século 18, o governo biopolítico passa a produzir um conjunto de políticas de produção da vida de determinadas populações, em detrimento de outras populações que são abandonadas à morte por não serem abrangidas por determinadas tecnologias biopolíticas.

A "necropolítica" de Achille Mbembe dá prosseguimento ao pensamento foucaultiano, propondo que existe um outro tipo de poder, baseado no "fazer viver" de determinados indivíduos a partir do "fazer morrer" de outros indivíduos. Essa necropolítica é colocada em prática a partir da racialização e do racismo, assim como da criação de um estado de exceção, no qual pode ocorrer uma matança generalizada e irrestrita. Segundo Mbembe, o governo das vidas e das mortes no Sul Global continua sendo necropolítico, em razão da permanência da dominação colonial, e o genocídio da população não branca é um reflexo dessas políticas de produção massificada de mortes. Como ensina Sueli Carneiro (2005), a configuração do exercício do poder nos territórios colonizados evidencia os princípios operativos da necropolítica, pois o "fazer viver" é dirigido aos corpos brancos para sustentar a sua existência a partir do "fazer morrer" do outro não branco. 
É imprescindível mencionar que o conceito de "raça", ou mais especificamente o "racismo", possui um lugar proeminente na racionalidade necropolítica. Embora a correlação de biopolítica e racismo não seja inovadora, pois Foucault já havia feito em sua teoria ${ }^{2}$, Mbembe inova, ao inscrever a genealogia do racismo em uma temporalidade alternativa àquela que sustenta a origem do genocídio nas formações sociopolíticas da Europa Ocidental e que o racismo de Estado só esteve presente no holocausto de judeus. Nos espaços coloniais e neocolonais, como o Brasil, também há uma dinâmica de "fazer viver" corpos brancos e "fazer morrer" corpos não brancos, muito embora os casos menos reconhecidos de genocídio nas esferas política e jurídica sejam aqueles cujo crime é cometido por algozes brancos e as vítimas são não brancas (FLAUZINA, 2014, p. 137).

Contudo, é importante saber que foi apenas a partir da invenção de "raça" como categoria social que o racismo pôde aparecer enquanto estratégia indispensável da necropolítica. Conforme sustenta Aníbal Quijano (2005, p. 19), a partir da racialização dos povos originários das Américas e Caribe como "índios" e dos povos africanos como "negros", foi criado o primeiro sistema de classificação social básica e universal dos indivíduos da espécie marcando sua entrada na história humana e "raça" foi colocada como a primeira classificação social global da história. Em outras palavras, a categorização e a hierarquização dos seres humanos por raças e suas respectivas definições a partir da cor surgiram com o colonialismo como forma de naturalizar e justificar a dominação dos europeus sobre os não europeus, além de constituírem a grade de hierarquização nas colônias.

Em torno de "raça" foram articuladas múltiplas formas de desumanização "nas relações intersubjetivas e nas práticas sociais de poder", que introduziram no imaginário e nas relações sociais com os negros e indígenas "a ideia de que os não-europeus tem uma estrutura biológica, não apenas diferente daquela estrutura biológica dos europeus, mas sobretudo pertencente a um tipo ou a um

\footnotetext{
${ }^{2}$ Na obra Em Defesa da Sociedade, Foucault (2005) relaciona o conceito de biopolítica ao genocídio das populações como prática de extermínio do Estado, explicando que tanto o poder da morte quanto o poder da vida são exercidos a partir do racismo num sistema político centrado no biopoder. $\mathrm{O}$ filósofo entende que o racismo é o mecanismo fundamental do poder e estabelece um corte entre o que deve viver o que deve morrer, defasando no interior da população uns grupos em relação aos outros, isto é, fragmentando o contínuo biológico a que se dirige o biopoder. A morte do outro, a morte da raça ruim, da raça inferior (ou ainda do degenerado, ou do anormal), é o que vai deixar a vida em geral mais sadia, mais sadia e mais pura (FOUCAULT, 2005, p. 304-305). Desta forma, Foucault defende que o racismo tem extrema importância no exercício do biopoder, pois é a condição para se exercer o direito de matar, de maneira direta ou indireta, ao se expor a morte, multiplicar para alguns o risco de morte, ou ainda produzir a morte política, a expulsão, a rejeição. Como finaliza o filósofo francês, "a função assassina do Estado só pode ser assegurada, desde que o Estado funcione no modo do biopoder, pelo racismo" (FOUCAULT, 2005, p. 306). Achille Mbembe (2016, p. 128) explica que, em termos foucaultianos, o racismo é uma tecnologia destinada a permitir o exercício do biopoder, regulando a distribuição da morte e assegurando as funções assassinas do Estado. Nesse contexto de racismo como tecnologia de poder, a escravidão aparece como "uma das primeiras instâncias de experimentação biopolítica. Em muitos aspectos, a própria estrutura do sistema de colonização e suas consequências manifesta a figura emblemática e paradoxal do estado de exceção" (MBEMBE, 2016, p. 130).
} 
nível inferior" (QUIJANO, 2014, p. 20). Embora abolidas formalmente a escravidão e a servidão, o sistema de controle pautado na categoria de "raça" permaneceu vigente, existindo ainda reflexos visíveis daquela divisão, sobretudo na América Latina, onde as classes sociais são racializadas. De toda forma, considerando que nas Américas e no Caribe houve um entrecruzamento do extermínio das populações originárias e da escravidão dos povos africanos, não causa espanto que represente até hoje o caso mais extremo da colonização empreendida pela Europa ${ }^{3}$.

Achille Mbembe vê nas colônias e na colonização o local onde o necropoder se organizou de forma mais evidente e categórica, razão pela qual as experiências coloniais ligadas à escravidão devem ser, inevitavelmente, a grade de inteligibilidade para a violência e o terror contemporâneo gerado pela necropolítica. Segundo o autor, a criação de espaços de exceção nas ocupações coloniais foi essencial para a produção de políticas de extermínio, pois nelas a necropolítica elimina qualquer ideia de proibição de abate ou matança generalizada, uma vez que, sendo ameaçado, o soberano pode matar sem distinção quem julgar como seu inimigo (MBEMBE, 2011, p. 136).

Para assegurar que nesses locais o limite da morte terminasse, a territorialização os caracterizou como fronteiras habitadas por "selvagens", e assim as tornou espaços de formação do terror, de estado de exceção e de matabilidade dos povos indígenas. Mbembe (2016, p. 135) pontua que a "ocupação colonial" em si era uma questão de apreensão, demarcação e afirmação do controle físico e geográfico, de forma a inscrever sobre o terreno um novo conjunto de relações sociais e espaciais:

Essa inscrição (territorialização) foi, enfim, equivalente à produção de fronteiras e hierarquias, zonas e enclaves; a subversão dos regimes de propriedade existentes; a classificação das pessoas de acordo com diferentes categorias; extração de recursos; e, finalmente, a produção de uma ampla reserva de imaginários culturais. Esses imaginários deram sentido à instituição de direitos diferentes, para diferentes categorias de pessoas, para fins diferentes no interior de um mesmo espaço; em resumo, o exercício da soberania. $\mathrm{O}$ espaço era, portanto, a matéria-prima da soberania e da violência que sustentava. Soberania significa ocupação, e ocupação significa relegar o colonizado em uma terceira zona, entre o status de sujeito e objeto (MBEMBE, 2016, P. 135)

\footnotetext{
${ }^{3}$ Ressalte-se que, durante a expansão do colonialismo europeu, novas identidades históricas, sociais e geoculturais foram produzidas sobre os mesmos fundamentos de uma imposição da categoria "raça". Ao longo desse processo de dominação colonial, foram acrescentadas às identidades de "índios", "negros", "brancos" e "mestiços", "amarelos", "oliváceos" ou "azeitonados", conforme emergia uma nova geografia do poder e uma nova territorialização de colônias. A identificação e classificação de "novos mundos", Europa, Europa Ocidental, América, Ásia, África, Oceania, e de outro modo, Ocidente, Oriente, Oriente Próximo, Extremo Oriente, foi acompanhada das respectivas identificações e classificações de novas "culturas", "nacionalidades" e "etnicidades" (QUIJANO, 2005, p. 19).
} 
Achille Mbembe (2016, p. 135) faz referência a Frantz Fanon para analisar as ocupações coloniais contemporâneas, explicando que Fanon apresenta uma leitura espacial da ocupação colonial. Para este último filósofo, a ocupação colonial implicaria uma divisão do espaço em compartimentos e envolveria a definição de limites e fronteiras internas por quartéis e delegacias de polícia. Essa espacialização da ocupação colonial definiria quem importa e quem não importa, quem é “descartável” e quem não é. Na obra Condenados da Terra, Frantz Fanon (p. 39) aborda a "cidade do colonizado", um lugar de má fama, povoado de homens de má reputação, que pouco importa onde, como e quando morrem.

A partir disso, verifica-se que o aporte teórico oferecido por Achille Mbembe nos permite alargar as reflexões foucaultianas sobre biopolítica, uma vez que se admite que ele não apenas exercido quanto à vida, mas também no nível da morte, na possibilidade de matabilidade e na ideia de que qualquer um pode ser soberano e decidir pela morte do outro, conforme conclui Fátima Lima (2018, p. 30). Esse deslocamento conceitual-metodológico é importante, a fim de pensarmos e posicionamo-nos acerca das engrenagens necropolíticas que existem no contexto brasileiro, uma vez que

o poder necropolítico se faz visível no sistema carcerário, na população em situação de rua, nos apartheids urbanos nas grandes e pequenas cidades brasileiras, em dados relevantes, no genocídio da população negra que em sua maioria é jovem e masculina, na eclosão dos grupos de justiceiros, nos hospitais psiquiátricos, nas filas das defensorias públicas, nas urgências e emergências hospitalares, entre tantos outros lugares (...) esses dados nos colocam frente a situações que exigem reflexões e tomadas de posições mais agudas no enfrentamento das práticas racistas como engrenagens bionecropolíticas que, na raça, ou melhor, nas práticas racistas e nas ideias de raças contemporâneas, ainda um grande delírio (LIMA, 2018, p. 28)

Dessa maneira, neste trabalho, propõe-se utilizar a grade teórica de Achille Mbembe para analisar as políticas de morte antigas e atuais direcionadas aos povos indígenas do Brasil. Justificase essa proposta epistemológica pelo fato de o colonialismo instalado no Brasil ter por base um paradigma racista que necessita da produção de mortes dos povos indígenas e de outros povos não brancos, para que a vida do povo branco possa existir. Essa política genocida de extermínio populacional ocorre num arranjo espacial de estado de exceção permanente, no qual se assenta uma matança generalizada de indígenas desprovidos de status político e reduzidos a seus corpos biológicos. 


\section{NECROPOLÍTICA DOS POVOS INDÍGENAS NO BRASIL: DO BRASIL COLÔNIA AO BRASIL DO AGRONEGÓCIO}

Ao discutir a necropolítica nos espaços marcados pela experiência colonial, é possível dizer que a ocupação colonial brasileira foi viabilizada pela realização de um projeto governamental necropolítico, pautado no racismo e na territorialização, conforme proposto na teoria de Achille Mbembe. No Brasil Colônia, a racialização ${ }^{4}$ dos povos indígenas como "índios” permitiu a ocupação territorial dos espaços que outrora eram desses povos, a partir da marcação, neutralização e eliminação desses indivíduos. Esse genocídio não foi acidental, pois, na maioria dos casos, ocorreu com a chancela governamental, uma vez que a aniquilação de povos indígenas de certos espaços facilitaria a ocupação, o povoamento, o incremento da imigração e a colonização europeia, a expansão da agricultura, do pastoreio e da industrialização e, por fim, da tão almejada "civilização do Brasil".

É possível afirmar que a usurpação das terras tradicionais se configurou como uma técnica de territorialização voltada à necropolítica e à produção de mortes em massa, conforme os colonizadores foram varrendo os grupos autóctones de certos espaços ou confinando-os em aldeamentos, por meio da catequização e de políticas indigenistas. Isso contribuiu para destruir as instituições econômicas e culturais desses povos, posto que a identidade dos povos originários se encontra essencialmente vinculada ao seu território e à sua terra. Em decorrência da necropolítica dos povos indígenas, pautada na territorialização, que Manuela Carneiro da Cunha afirma que o Brasil indígena hoje não passa de fragmentos "e um tecido social cuja trama, muito mais complexa e abrangente, cobria provavelmente o território como um todo" (CUNHA, 2008, p. 12).

A territorialização dos espaços naturais ocupados pelos povos indígenas aparece como estratégia do governo necropolítica, uma vez que as terras tradicionalmente ocupadas por esses povos representam o suporte de etnicidade, vida social, cultura, tradições e crenças da comunidade indígena. A relação dos povos indígenas com suas terras e seus territórios tradicionais afeta a própria noção de identidade, pois esses povos associam sua subjetividade ao locus onde vivem, ao ponto de suas próprias existências dependerem dela. Sendo assim, tanto a terra quanto o território possuem um valor de sobrevivência física, econômica e cultural para os povos indígenas, e também de

\footnotetext{
4 Achille Mbembe (2011,p. 10) sustenta que os processos de racialização das colônias visavam marcar determinados grupos de populações, como os "índios" e os "negros", fixando do modo mais preciso possível o limite de até onde podem circular, de quais espaços elas podem ocupar, assegurar as circulações, afastando as ameaças e garantindo a segurança geral. A raça, deste ponto de vista, funciona há um tempo como ideologia, dispositivo de segurança e tecnologia de governo das multiplicidades desses grupos de populações, e permite-os marcar como “espécies” e, se possível, neutralizálos antecipadamente, frequentemente por meio do encarceramento, da deportação e do genocídio.
} 
autodeterminação, razão pela qual seu esbulho representou (e representa até hoje) uma forma de extermínio desses povos.

A partir da territorialização, outras tecnologias necropolíticas são colocadas em prática para assegurar a produção de morte desses povos. Por exemplo, Darcy Ribeiro (1996) afirma que as doenças consistiram no primeiro fator interveniente no genocídio físico das populações indígenas no Brasil. Enfermidades como gripe, sarampo, catapora, varíola, malária, pneumonia, febre amarela e, em certa medida, tuberculose, foram levadas pela "civilização" de fora do continente americano, e não encontraram resistência imunológica entre os povos indígenas. Assim que os colonizadores tomaram consciência da vulnerabilidade dos indígenas aos patógenos, não mediram esforços e nem escrúpulos, e valeram-se das doenças para promover o extermínio de aldeias e povos indígenas, ou seja, travou-se o que, atualmente, conhecemos por guerra bacteriológica.

Como relata José de Anchieta (1988, p. 356), na época da ocupação colonial brasileira, as enfermidades que acometiam os indígenas debilitavam seus corpos para as práticas sociais cotidianas, impediam-nos de coletar, recolher e produzir os alimentos necessários, o que acarretava, em muitos casos, morte pela fome, antes mesmo que pela doença. Dessa forma, se aldeias inteiras não eram dizimadas, aqueles que sobreviviam fugiam da aldeia, das moléstias e do colonizador portador de patógenos, vindo a vaguear pelo território. Essas epidemias, disseminadas na maioria das vezes de forma intencional e programada, refletem o espírito cruel e desumano dos colonizadores e representam a perversa intenção genocida do governo colonizador, e permaneceram sendo utilizadas como técnicas de genocídio, inclusive, após a independência do Brasil.

Tão ou mais devastador do que as epidemias e doenças foram os conflitos e as guerras emergidas entre indígenas e colonizadores. Ao cobiçarem as terras indígenas, os portugueses deram início a diversas guerras de extermínio contra povos indígenas com o intuito de se apropriar de seus territórios tradicionais. Pelo fato de a heterogeneidade étnica ter sido um dos problemas mais complexos da colonização, os conflitos entre colonizadores e povos indígenas se davam a partir da criação de demarcadores étnicos genéricos, categorizando grupos étnicos como "amigos" ou “inimigos", "selvagens" e "civilizados”, “Tupis" e "Tapuios” (PRADO JR, 2011, p. 94). A título de exemplo de conflitos envolvendo estes quadros de demarcações étnicas, Oliveira e Freire (2006, p. 53) mencionam a Confederação dos Tamoios e a Guerra dos Bárbaros.

Se por um lado, o Brasil, com a instauração da República, passa a reconhecer os direitos dos povos indígenas, por outro, exerce o controle sobre a vida por meio do poder tutelar e das políticas indigenistas, o qual implica um controle da vida no sentido biopolítico. Segundo Lima (1995), o poder 
tutelar sobre os indígenas é uma manifestação da biopolítica, pois violenta e reprime pela dominação, produz e controla pela produção da subjetividade, conforme a norma, o que legitima a violência contra o comportamento fora da norma. Contudo, esse poder tutelar tem características necropolíticas, já que as políticas indigenistas acarretavam "morte física por guerra aberta ou por pacificação, necessária redução dos efetivos humanos a quebrar solidariedades e a facilitar outro tipo de morte, a da alteridade" (LIMA, 1995, p. 308).

A ditadura militar brasileira, instaurada pelo Golpe de 1964, constituiu provavelmente um dos períodos mais mortais para os povos indígenas brasileiros, pois diversas formas, técnicas e vários instrumentos modernos de eliminação de seres humanos foram empregados pelos militares, a saber: campos de trabalho forçado, prisões específicas para indígenas, omissão de vacinação de maneira proposital, omissão de atos preventivos em conflitos de fazendeiros e indígenas e omissão da prevenção das violações sexuais atentadas às mulheres indígenas. Alvarenga \& Américo Júnior (2019, p. 221) apontam que a necropolítica, durante o regime de exceção no Brasil, deu-se pela criação de um campo de batalha nos territórios indígenas, já que tropas eram encaminhadas para eliminar diretamente as aldeias, por meio de armamentos, metralhadoras, incêndios e envenenamento de rio.

Tendo em vista essas práticas genocidas, o relatório final da Comissão Nacional da Verdade (CNV) computa como mortes provocadas pelo regime militar entre os povos indígenas: "Cerca de 1.180 Tapayuna, 118 Parakanã, 72 Araweté, mais de 14 Arara, 176 Panará, 2.650 Waimiri-Atroari, 3.500 Cinta-Larga, 192 Xetá, no mínimo 354 Yanomami e 85 Xavante de Marãiwatsédé” (CNV, 2014, p. 254). Contudo, a própria Comissão ressalta que os números reais de mortes devem ser exponencialmente maiores. Além do extermínio físico por meio de chacinas e massagres, Helena Palmquist (2018, p. 115) menciona que, nesse período, os povos indígenas também foram assolados pela fome e por epidemias, tendo em vista a política de integração regional e a política de atração e o contato com povos isolados, sem as precauções sanitárias necessárias.

De maneira geral, a política de integração regional iniciada no período ditatorial resultou no extermínio, segundo o cálculo mais conservador apresentado pela Comissão Nacional da Verdade, de pelo menos 8.341 indígenas, em massacres, epidemias e fomes. Esses dados evidenciam que o Estado brasileiro desse período operava administrativamente com a morte enquanto forma de proporcionar desenvolvimento e progresso para a sociedade. Com a queda da ditadura e a instauração da Nova República, uma outra composição de forças foi determinada pela acumulação do capital e pelo neoliberalismo. 
Nas últimas décadas, foi consolidado no Brasil um governo do território corporativo do agronegócio brasileiro, daí o país se encontrar comandado por uma economia política do agronegócio, que tem sido ditado por grandes corporações transnacionais. Dessa maneira, o governo brasileiro atua para a expansão e ampliação dos territórios corporativos do agronegócio a partir de políticas de produção de morte, ao realizar um ataque a toda forma livre de vida, anulando políticas públicas, dispositivos administrativos e legislativos de defesa para os povos indígenas. Essa necropolítica do agronegócio opera em torno do extermínio dos povos indígenas que sobreviveram ao genocídio no período colonial.

Para ilustrar a situação acima descrita, aponta-se que a necropolítica brasileira contemporânea constrói dispositivos político-jurídicos de flexibilização da legislação ambiental para permitir atividades de mineração e parceiras do agronegócio para produção agrícola em terras indígenas, retomando os discursos e as práticas de integração do indígena à sociedade nacional pelo mercado capitalista do período da ditadura militar brasileira. Além disso, o desmanche da FUNAI, que sobrevive no limiar da inoperância com restrições orçamentárias e de pessoal, assim como as tentativas de extinguir a Secretaria Especial de Saúde Indigenista (SESAI) no âmbito no Ministério da Saúde (MS) junto à União, com o objetivo de municipalizar a saúde, sem o atendimento diferenciado, evidenciam que o novo governo se posiciona contra as vidas indígenas.

Em acréscimo a isso, o "Relatório de violências contra os povos indígenas no Brasil” (2019), publicado pelo Conselho Indigenista Missionário (CIMI), revela os números alarmantes da violência contra povos indígenas no país. O Relatório aponta que, em 2019, houve o aumento de casos em 16 das 19 categorias de violência sistematizadas pela publicação. Chama especial atenção a intensificação de registros na categoria "invasões possessórias, exploração ilegal de recursos e danos ao patrimônio" que, os 109 casos registrados em 2018, saltaram para 256 em 2019. Infelizmente, as violências praticadas contra os povos indígenas fundamentam-se em um projeto de governo que pretende disponibilizar suas terras e os bens comuns nelas contidos aos empresários do agronegócio, da mineração e das madeireiras, dentre outros.

A usurpação das terras e dos territórios tradicionais, o etnocídio, a disseminação deliberada de doenças, as guerras e conflitos armados são exemplos de um conjunto de processos de extermínio físico e simbólico dos povos indígenas que marcou o período colonial e acarretou a redução drástica dessa população. Segundo dados do $\operatorname{IBGE}(2007$, p. 232; 2010), estima-se que existiam entre 1 milhão a 6,8 milhões de nativos, número que contrasta fortemente com a quantidade atual de indígenas no Brasil, considerada de aproximadamente 896,9 mil indígenas, 36,2\% em área urbana e 63,8\% na área 
rural. A necropolítica dos povos indígenas já existia no período colonial brasileiro, muito antes do conceito ter sido formulado por Achille Mbembe, pois é óbvio que a realidade antecede, e muito, o conceito.

A partir das reflexões trazidas, conclui-se que a necropolítica permanece institucionalizando a exclusão social, a violência estatal e paraestatal e o genocídio contra os povos indígenas, a partir de diversas formas, técnicas e vários instrumentos modernos de eliminação de seres humanos, que aparentam "novidades" do mundo contemporâneo, entretanto apenas revisitam as antigas políticas de produção de morte que datam do período colonial. Essa política de morte contemporânea, guiada pelos interesses do mercado e do agronegócio, atualiza o genocídio físico e o etnocídio contra os povos indígenas, pois implica o poder de comandar quem deve viver e quem deve morrer. Nesse contexto, a disputa em torno dos territórios indígenas desponta como um pacote de tecnologias necropolíticas, que respondem aos interesses neoliberais de produção de mortes.

\section{NECROTERRITÓRIO: TERRITORIALIZAÇÃO E DESTERRITORIALIZAÇÃO COMO ESTRATÉGIAS NECROPOLÍTICAS}

No presente trabalho, considerando os territórios esbulhados dos povos indígenas pelos colonizadores e os territórios que permanecem em disputa entre os povos indígenas e o agronegócio, compreende-se que o território é uma tecnologia política. Stuart Elden (2013, pp. 322-323) defende que o território deve ser entendido como um pacote de tecnologias políticas, por consistir num conjunto de técnicas para medir terras, no sentido político-econômico, e controlar o terreno, no sentido político-estratégico. Admitindo o território como um dos objetos centrais dos estudos das relações de poder, Rogério Haesbaert (2004, p. 93) define o território relacionalmente enquanto mediação especial do poder, resultante da interação diferenciada entre as múltiplas dimensões desse poder.

Compreender o território enquanto uma tecnologia política permite compreender como os territórios podem servir aos interesses da necropolítica do agronegócio. Em outras palavras, a ampliação das fazendas do agronegócio e a destruição das terras indígenas são formas de mediação de terras e controle de terrenos pautados na produção de mortes de determinados povos sob uma gestão necropolítica. Conforme explica Porto-Gonçalves (2002), o espaço agrário se caracteriza por relações de poder que primam pela violência e têm como cerne a histórica concentração fundiária, 
consagraram a profunda injustiça social, violência e morte que subjazem a esse contraditório padrão de poder.

Assim, o território, na teoria de Rogério Haesbaert (2004, p. 97), é um produto revelado por diferentes processos de "territorialização", isto é, agenciamentos, por meio dos quais um determinado indivíduo ou determinado grupo social dota de significado o espaço físico ou virtual de convivência. Segundo o autor, a territorialização possuiria quatro finalidades: apropriação do abrigo físico de uma fonte de recursos materiais e dos meios de produção; identificação de grupos de interesse mediante as dimensões espaciais e fronteiras geográficas; controle do espaço, por meio dos espaços individualizados; e construção/controle de conexões e redes.

Pensando a territorialização como estratégia da necropolítica brasileira, percebe-se que diversos territórios indígenas e periféricos passaram a ser territorializados, simultânea e progressivamente, como áreas de interesse econômico de fazendeiros e grandes empresas, e como territórios de inimigos, que precisam ser dizimados e contidos por milícias privadas e forças policiais. Considerando que o território pode ser um conjunto de tecnologias (necro)políticas e que a territorialização seria uma estratégia para assegurar essas políticas de produção de mortes e de vidas, o terror e o anti-terror aparecem como técnicas necropolíticas para criar a ideia de que a integridade do Estado-nação está sendo ameaçada por esses "inimigos do Estado" e de que é necessária a instituição de um Estado de exceção.

Ao comparar as populações originárias à figura de um bandido ou terrorista, tais discursos conseguem aproximar os indígenas da figura agambeniana do homo sacer ${ }^{5}$, colocando-os em uma zona indistinta, na qual ele não está simplesmente excluído da lei, mas sim abandonado por ela, tornando-se vulnerável em um espaço onde as distinções entre dentro e fora, vida e morte, tornam-se confusas.

Ao passarem por esses processos de territorialização, espaços físicos, como o Cerrado e a Amazônia, são separados, categorizados e segmentados em territórios específicos, nomeados de "reservas indígenas", "territórios tradicionais", "áreas de preservação", para então serem dotados de um significado particular que legitima a produção de mortes dos povos originários. É possível dizer

\footnotetext{
${ }^{5}$ Os indígenas, situados nesse necroterritório, assemelham-se à figura do homo sacer proposta por Giorgio Agamben (2007). De fato, o que peculiariza a condição do homo sacer é sua dupla exclusão em relação ao campo religioso e ao campo jurídico, não sendo reconhecido, nem legitimado, em nenhum desses espaços. Além disso, outra peculiaridade seria o fato do homo sacer estar permanentemente exposto à violência, encarando diariamente a possibilidade de ser morto sem que haja qualquer sanção ao autor do homicídio (AGAMBEN, 2007, p. 90-91). Nesse caso, verifica-se que os povos indígenas, principalmente no contexto brasileiro, poderiam ser apontados como formas de vida que se aproximam do conceito agambeniano de homo sacer, tanto pela sua insacrificabilidade, quanto pela sua matabilidade.
} 
que esses espaços se transformam em necroterritórios ou, conforme prefere chamar Achille Mbembe (2018, p.71), “topografias recalcadas de crueldade". Para os povos indígenas e tradicionais, esses necroterritórios são uma "contenção territorial” (HAESBAERT, 2008), nas quais a territorialização regula e cerceia o ir e o vir dos povos e assegura o monopólio da violência e do poder de morte sobre essas pessoas.

A territorialização, estratégia de produção da necropolítica, dota de significado os territórios indígenas a partir de uma lógica de inferiorização e de colocação desses povos numa "zona de nãoser", como proposto por Sueli Carneiro (2005). Pelo fato de a interação dessas populações com seus territórios não ter valor econômico, não produzir acumulação de capital e não se aproximar da ânsia desenvolvimentista do capitalismo, esses territórios são entendidos como não territórios. Não por acaso, o atual governo brasileiro, representação fiel de um governo genocida, sustenta como uma de suas principais bandeiras que a conservação ambiental e as demarcações de terras aos povos indígenas e quilombolas são responsáveis pelo atraso econômico do país. Esse posicionamento evidencia que o dito desenvolvimento econômico representa, em última análise, políticas de genocídio ou uma necropolítica.

Além disso, o território também é revelado por um processo de "desterritorialização". Segundo Rogério Haesbaert (2004, p. 127), a desterritorialização pode significar a diminuição ou o enfraquecimento das fronteiras, com aumento da fluidez e mobilidade de pessoas, bens, capitais e informações. Pode também significar a desvinculação e reterritorialização devido à presença ou à ausência de "base física minimamente estável para sobrevivência do grupo, acesso a direitos fundamentais de cidadania no território nacional, identidade sociocultural com espaços específicos e referenciais simbólicos" (HAESBAERT, 2004). Mais ainda, muitos grupos sociais podem estar desterritorializados sem deslocamento físico, sem níveis de mobilidade espacial pronunciados, bastando que vivam uma precarização de vida e negação de sua expressão simbólico-cultural.

Nesse contexto de desterritorialização, aponta-se a intensificação das expropriações de terras tradicionais que ocorrem em todo o território nacional, a partir da invasão, da grilagem e do loteamento. Além disso, a proliferação de incêndios criminosos que devastaram a Amazônia e o Cerrado são parte essencial de uma técnica de desterritorialização necropolítica: os invasores expropriam as terras tradicionais, matam os indígenas que resistem à usurpação, expulsam os sobreviventes, desmatam a área, vendem as madeiras, tocam fogo na mata, iniciam as pastagens, cercam a área e, finalmente, com a área "limpa", colocam gado e, posteriormente, plantam soja ou milho, para serem vendidas no mercado externo. 
A desterritorialização indígena, com efeitos genocidas, também pode ser causada pela disputa por outros recursos naturais, tais como minério, borracha e madeira. No caso da Usina Hidrelétrica de Belo Monte, com sua conclusão, evidencia-se uma disputa pelo recurso mais essencial à vida: a água. Em uma ponta, a usina hidrelétrica, construída com base em argumentos de soberania nacional, desenvolvimento nacional, para quem interessa desviar o máximo possível de água da Volta Grande, uma vez que disso depende a produção de energia; na outra, comunidades indígenas com terras demarcadas ou não, para quem a água é determinante para sua permanência no território (PALMQUIST, 2018, p. 132).

Inspirado nos escritos de Deleuze e Guattari, Achille Mbembe 2016, p. 140), chama de “máquinas de guerra" as tecnologias necropolíticas responsáveis pela desterritorialização na busca de extração e exportação de recursos naturais. As máquinas de guerra são organizações polimorfas e difusas: podem se apresentar numa forma estatal, para-estatal, exércitos ou até mesmo empresas mercantis. Elas incorporam elementos de fragmentação espacial e desterritorialização com o objetivo de comandar e regulamentar o acesso aos recursos naturais dentro do território. No contexto brasileiro, as "máquinas de guerra" podem ser o mercado neoliberal, as empresas transnacionais e o próprio Estado brasileiro e suas instituições que aumentam e inflacionam o valor dos recursos naturais existentes nos territórios indígenas.

Essas máquinas de guerra tornam-se rapidamente mecanismos predadores altamente organizados, que taxam os recursos naturais, os territórios e as populações que os ocupam e assim geram a desterritorialização dos povos indígenas. Como ressalta Achille Mbembe (2016, p. 141), a extração e o saque dos recursos naturais pelas máquinas de guerra caminham de mãos dadas com tentativas brutais para imobilizar e fixar espacialmente categorias inteiras de pessoas ou, paradoxalmente, para soltá-las, forçando-as a se disseminar por grandes áreas que excedem as fronteiras de um Estado territorial. Nesse sentido, pela desterritorialização se criam novas territorialidades.

É por essa razão que, em necroterritórios, a desterritorialização faz parte de um conjunto de estratégias necropolíticas reguladoras da distribuição de morte desses povos "desterritorializados". Para Rogério Haesbaert (2004, p. 367), o pano de fundo da desterritorialização acaba sendo o neoliberalismo, que prega o "fim das fronteiras" e o "fim do Estado" para a livre atuação das forças do mercado. Nesse caso, o que desterritorializa é justamente a ausência ou o afastamento do Estado brasileiro frente ao poder do capital do agronegócio. Não são os grandes empresários e latifundiários que estão "desterritorializados", pois eles têm a liberdade de escolher a territorialidade que mais lhes 
convém, forjando assim a desterritorialização dos povos indígenas e tradicionais com o agravamento da desigualdade social, da exclusão pela concentração de renda e da ausência de políticas efetivas de redistribuição.

A partir das reflexões trazidas, conclui-se que a necropolítica decorre da capacidade de o Estado decidir quem vai morrer e quem vai viver a partir de políticas de extermínio, genocídio e morte. Esse necropoder mantém uma continuidade colonial centrada desde sempre na apropriação dos territórios indígenas como pressuposto do desenvolvimento econômico, inscrevendo as populações originárias no "signo da morte", nas palavras de Sueli Carneiro (2005). A territorialização cria, ao mesmo tempo, um território de interesse econômico e um território de inimigos, sobre os quais incidem as máquinas de guerra e o terror, que operam a desterritorialização. Entre esses movimentos concomitantes de territorialização e desterritorialização, os necroterritórios aparecem como "topografias recalcadas de crueldade" (MBEMBE, 2016), "contenção territorial" (HAESBAERT, 2008), “campo” (AGAMBEN, 2007) e “zonas de não-ser” (CARNEIRO, 2005).

Diante disso, propõe-se a ampliação do conceito de território enquanto técnica (necro)política, de forma a permitir a compreensão das lutas contra-hegemônicas em torno da ocupação colonial contemporânea brasileira. Haesbaert (2014, p. 55) afirma que, nos últimos tempos, a problemática do território se tornou uma questão central no contexto brasileiro devido à luta pela terra e, para analisar as questões territoriais contra-hegemônicas da contemporaneidade, é necessária a distinção entre território como categoria de análise, como categoria da prática e como categoria normativa:

A relevância em distinguirmos o conceito de território enquanto categoria de análise, categoria da prática e, também, categoria normativa. Essas formas de ler o território precisam, em certas situações, ser mais claramente distinguidas, sob pena de confundirmos (algo que é feito com relativa frequência) a utilização do termo nas práticas do senso comum, cotidianas (categoria da prática), como instrumento intelectual em nossas pesquisas (categoria de análise) e como ferramenta para a ação política, em especial o planejamento (categoria normativa). Entretanto, também não podemos cair no extremo oposto, ignorando que elas estão, frequentemente, em franco diálogo e ampla interseção (HAESBAERT, 2016, p. 29-30)

Essa ampliação do conceito enquanto categoria analítica de investigação deve se dar a partir de uma análise mais atenta ao modelo hegemônico capitalista no qual o território é construído, aos distintos sujeitos envolvidos nesses conflitos e nas técnicas políticas empregadas. Sendo assim, é preciso lembrar as disputas em torno do território que datam desde o período colonial e permanecem quando da inserção do país na periferia do capitalismo neoliberal. Ainda, não podem ser esquecidas as reivindicações dos territórios indígenas nos mais diversos campos de poder, como o político 
(representação política em oposição ao interesse do agronegócio e da bancada rural), o jurídico (reconhecimento do direito de demarcação de terras tradicionais e criação de reservas indígenas) e até mesmo o simbólico (suporte de etnicidade, vida social, cultura, tradições e crenças da comunidade indígena).

Sem a demarcação dos territórios tradicionais, os povos indígenas permanecem vulneráveis à morte, sobrevivendo e resistindo em microespaços, pequenas áreas espremidas entre fazendas, lavouras do agronegócio, entre rodovias e cercas. Os povos originários então lutam pela sobrevivência, a fim de continuarem suas reivindicações em contextos de conflitos, de confrontos, a ataques químicos, provenientes de pulverização descontrolada e irresponsável de agrotóxicos e envenenamento das águas. Nesse sentido, as retomadas de territórios tradicionais podem ser consideradas alternativas descoloniais para superar as desigualdades, nas palavras de Ramón Grosfoguel (2008), e um caminho para a construção de uma biopolítica afirmativa, nas palavras de Roberto Esposito (2017). Em suma, os territórios de retomada podem consistir em políticas de vida, em oposição às políticas de morte.

\section{CONSIDERAÇÕES FINAIS}

A partir das reflexões trazidas, foi possível compreender o processo de genocídios de que os povos indígenas foram vítimas ao longo dos séculos. A usurpação das terras e dos territórios tradicionais, o etnocídio, a disseminação deliberada de doenças, as guerras de extermínio e as chacinas por forças militares foram apontados como parte de um conjunto de processos de extermínio físico e simbólico dos povos indígenas que levaram à redução drástica dessa população. A partir de técnicas e instrumentos modernos de eliminação de seres humanos, que aparentam "novidades" do mundo contemporâneo, o governo necropolítico brasileiro revisita as antigas políticas de produção de morte que datam do período colonial e adaptam para responder aos anseios do agronegócio e do grande capital.

Com o aprofundamento dos pensamentos de Achille Mbembe acerca do território, a necropolítica aparece como uma técnica de poder voltada para o controle e regulação da população, baseada no "fazer viver" de determinados indivíduos a partir do "fazer morrer" de outros indivíduos. No contexto brasileiro, o colonialismo instalado no Brasil foi assentado em um paradigma racista que necessita da produção de mortes dos povos indígenas, assim como de outros povos não brancos, para que a vida do povo branco possa existir. Essa política genocida de extermínio populacional ocorre 
num arranjo espacial de estado de exceção permanente, no qual repousa uma matança generalizada de indígenas desprovidos de status político e reduzidos a seus corpos biológicos.

Sendo assim, retomando a indagação de pesquisa, no sentido de compreender de que modo o território pode ser uma tecnologia necropolítica de genocídio dos povos indígena, conclui-se que, no contexto brasileiro, os territórios são necroterritórios, nos quais os processos de territorialização e desterritorialização capturam as vidas dos povos indígenas e produzem seu extermínio em massa. Esses necroterritórios são também denominados de "topografias recalcadas de crueldade" (Achille Mbembe), "campo" (Giorgio Agamben), "zonas de não-ser" (Sueli Carneiro) e "contenção territorial” (Rogério Haesbaert).

A territorialização delimita os territórios indígenas a partir de um discurso de inferiorização dos territórios tradicionais, regula e cerceia o ir e o vir dos povos, assim como assegura o monopólio da violência e do poder de morte sobre essas pessoas. Ao mesmo tempo, ocorre um processo expropriatório de desterritorialização desses povos, já que eles são expulsos do território pelo funcionamento de máquinas de guerra que taxam os recursos naturais, os territórios e as populações que os ocupam. A territorialização e desterritorialização das terras tradicionais indígenas aparecem como tecnologias necropolíticas, cujo efeito derradeiro é o extermínio dos grupos étnicos inseridos na disputa em torno desses territórios.

\section{REFERÊNCIAS}

ALVARENGA, Rodrigo \& AMÉRICO JUNIOR, Elston. Da biopolítica à necropolítica contra os povos indígenas durante a ditadura militar brasileira (1964-1985). Ciências Sociais Unisinos, São Leopoldo, Vol. 55, N. 2, p. 212-222, mai/ago 2019

ANCHIETA, José de. Cartas: informações, fragmentos históricos e sermões. Cartas Jesuíticas 3. Belo Horizonte: Itatiaia; São Paulo: Ed. USP, 1988.

CARNEIRO, Sueli. A construção do outro como não-ser como fundamento do ser. Tese de Doutorado do programa de Pós-Graduação em Educação da Universidade de São Paulo, 2005.

CUNHA, Manuela Carneiro da. História dos índios no Brasil. São Paulo: Companhia das letras, 2008.

ELDEN, Stuart. The birth of territory. Chicago: University of Chicago Press, 2013.

ESPOSITO, Roberto. Bios: biopolítica e filosofia. Belo Horizonte: Editora UFMG, 2017.

GROSFOGUEL, Ramón. Para descolonizar os estudos de economia política e os estudos póscoloniais: Transmodernidade, pensamento de fronteira e colonialidade global. Revista Crítica de 
Ciências Sociais, n. 80, março, 2008. Disponível em: https://doi.org/10.4000/rccs.697. Acesso em: 21/02/2021.

HAESBAERT, Rogério. Armadilhas do território. In: BORZACCHIELLO DA SILVA, J.; SILVA, C. N.M.; DANTAS, E. W. C. (Org.). Território: modo de pensar e usar. Fortaleza: EdUFC, 2016.

HAESBAERT, Rogério. Viver no limite: território e multi/transterritorialidade em tempos de insegurança e contenção. Rio de Janeiro: Bertrand Brasil, 2014.

HAESBAERT, Rogério. O mito da desterritorialização: do "fim dos territórios" à multiterritorialidade. Rio de Janeiro: Bertrand Brasil, 2004.

INSTITUTO BRASILEIRO DE GEOGRAFIA E ESTATÍSTICA. IBGE. O Brasil indígena. Rio de Janeiro: IBGE, 2010

INSTITUTO BRASILEIRO DE GEOGRAFIA E ESTATÍSTICA. IBGE. Brasil: 500 anos de povoamento. Rio de Janeiro: IBGE, 2007.

LIMA, Fátima. Bionecropolítica: diálogos entre Michel Foucault e Achille Mbembe. Revista Arquivos Brasileiros de Psicologia, Número 70, 2018. Disponível em: http://pepsic.bvsalud.org/scielo.php?script $=$ sci arttext\&pid $=\mathrm{S} 1809-$

52672018000400003\&lng=es\&nrm=iso Acesso em: 21/02/2021.

LIMA, A. C. S. Um grande cerco de paz: poder tutelar, indianidade e formação de Estado no Brasil. Petrópolis: Vozes, 1995.

MBEMBE, Achille. Políticas da Inimizade. Lisboa: Editora Antígona, 2017.

MBEMBE, Achille. Necropolítica. Revista Arte \& Ensaios, número 32, 2016.

MBEMBE, Achille. Necropolítica, una revisión crítica. In: GREGOR, Helena Chávez Mac (Org.). Estética y violencia: Necropolítica, militarización y vidas lloradas. México: UNAMUAC, 2012.

MBEMBE, Achille. A universalidade em Frantz Fanon. In: FANON, Frantz. Oeuvres. Paris: Editora La Découverte, 2011.

PRADO JR., Junior. Formação do Brasil Contemporâneo. São Paulo: Companhia das Letras, 2011, pp. 01-25

QUIJANO, Aníbal. Raza, etnia y nacion en Mariátegui: Cuestiones Abiertas. In: CLÍMACO, Danilo Assis (Org.). Cuestiones y horizontes: de la dependencia histórico-estructural a la colonialidad/descolonialidad del poder. Ciudad Autónoma de Buenos Aires: CLACSO, 2014

QUIJANO, Aníbal. Dom Quixote e os moinhos de vento na América Latina. Revista Estudos Avançados, volume 19, número 55, 2005. Disponível em: https://doi.org/10.1590/S010340142005000300002 Acesso em: 21/02/2021. 
RIBEIRO, Darcy. Os índios e a civilização. A integração das populações indígenas no Brasil moderno. São Paulo: Cia das Letras, 1996. 